\title{
Eosinophilic Esophagitis in Adults: A Concise Overview of an Evolving Disease
}

\author{
Amir Mari ${ }^{12, * *}$, Emmanouela Tsoukali ${ }^{3}$, Afif Yaccob ${ }^{4}$ \\ ${ }^{1}$ Gastroenterology Institute, Nazareth EMMS Hospital, Nazareth, Israel \\ ${ }^{2}$ The Azrieli Faculty of Medicine, Bar-Ilan University, Ramat Gan, Israel \\ ${ }^{3}$ Gastroenterology and Hepatology Department, Evangelismos General Hospital of Athens, Athens, Greece \\ ${ }^{4}$ Gastroenterology and Liver Disease Department, Rambam Healthcare Campus, Haifa, Israel
}

Eosinophilic esophagitis (EoE) is a chronic inflammatory disease that encompasses esophageal symptoms along with eosinophilic infiltration of the esophageal epithelium. EoE is an evolving disease that has been a subject of interest to many researchers since the first studies recognized this condition as a new and distinct clinicopathological entity 25 years ago. Clinical presentation in adult patients may include dysphagia, food impaction, vomiting, and reflux symptoms. The diagnosis of EoE is based on the combination of clinical history suggestive of esophageal dysfunction, endoscopic features indicative of the disease, and histology revealing eosinophilic infiltration of the esophageal epithelium that persists after a trial of proton pump inhibitor therapy along with the exclusion of other disorders that may be associated with esophageal tissue eosinophilia. The interplay between EoE and gastroesophageal reflux disease (GERD) is complex, and differentiating these two conditions continues to be difficult and challenging in clinical practice. The mainstay treatment includes dietary modification, topical steroids, and/or endoscopic dilation. The primary care physician (PCP) plays an important role in improving patient care and quality of life by ensuring early referral and participating in management and follow-up. This article provides an overview of the current knowledge base regarding the disease including epidemiology, genetics, pathogenesis, common clinical presentations, the interplay between EoE and GERD, diagnostic approaches, and therapeutic options available to the PCP.

Keywords: Eosinophilic Esophagitis; Diagnosis; Management; Primary Care Physicians

Received: September 13, 2018, Revised: October 8, 2018, Accepted: October 15, 2018

${ }^{*}$ Corresponding Author: Amir Mari https://orcid.org/0000-0002-6828-4738

Tel: +972-54-214-2070, Fax: +972-4-6028844, E-mail: amir_mari@nazhosp.com 


\section{INTRODUCTION}

Over the past 20 years, eosinophilic esophagitis (EoE) has dramatically emerged as a prevalent cause of gastrointestinal morbidity in adults. Classically, EoE has been defined as a chronic immune/antigen-mediated inflammatory condition of the esophagus, characterized clinically by esophageal symptoms of dysphagia and food impaction, and histologically by eosinophil-predominant inflammation (presence of $\geq 15$ eosinophils/high-power field in at least one esophageal biopsy), both of which are nonresponsive to prolonged acid suppression with proton pump inhibitors (PPIs). ${ }^{1)}$ Additionally, the exclusion of systemic and local causes of esophageal eosinophilia is mandatory for diagnosis (Table 1). ${ }^{1)}$ Since 2011, the most significant development in the definition of EoE has been linked to the growing concept of a distinct disease phenotype termed PPI-responsive esophageal eosinophilia (PPI-REE). ${ }^{1)}$ This phenotype describes patients with clinical, endoscopic, and histological features of EoE, all of which totally resolve on PPI therapy but are not necessarily associated with gastroesophageal reflux disease (GERD). ${ }^{2)}$

First described by Paul Ehrlich in 1879, the eosinophil is a non-specific inflammatory cell. ${ }^{3)}$ Hence, eosinophilic infiltration may be a common finding in numerous inflammatory and immunological conditions. In the 1980s, multiple case reports were published describing an eosinophilic infiltration of the esophagus-a tissue normally devoid of eosinophils-among patients experiencing symptoms of dysphagia, reflux disease, and other esophageal symptoms. ${ }^{4-7)}$ However, Attwood et al. ${ }^{8)}$ were the first to publish an article in 1993, titled "Esophageal eosinophilia with dysphagia, a distinct clinico-pathologic syndrome." In their case series, the authors described 12 adult-predominantly male-patients with dysphagia who exhibited a high concentration of intra-epithelial eosinophils in esophageal biopsies, normal endoscopy, and normal 24-hour esophageal pH monitoring, exhibiting a distinctive clinicopathological syndrome not previously described. This article alerted clinicians to a new syndrome affecting mainly young male patients with an allergic background who present with dysphagia and food impaction. In the past two decades, EoE has been extensively investigated around the world, paralleling the in-

Table 1. Diseases associated with esophageal eosinophilia

\begin{tabular}{l}
\hline \multicolumn{1}{c}{ Diseases } \\
\hline Eosinophilic gastroenteritis \\
Celiac disease \\
PPI-responsive esophageal eosinophilia \\
Crohn's disease \\
Vasculitis \\
Allergic reactions \\
Infections \\
Hyper-eosinophilic syndrome \\
Achalasia \\
Connective tissue diseases \\
PPI therapy
\end{tabular}

PPI, proton pump inhibitor. creasing incidence and prevalence of the disease. In the current review, we provide a concise, up-to-date summary of the disease, along with practical guidance for primary care physicians (PCPs) regarding diagnosis and management of patients with EoE.

\section{EPIDEMIOLOGY}

EoE is more common in Caucasian populations, with a male to female ratio of 3:1. ${ }^{9)}$ The prevalence is also increasing among African-American, Hispanic, and Asian populations, and is currently as high as 50 cases per 100,000 in the western population. Current incidence rates of EoE range between 6 and 13 new cases per 100,000 population per year in Europe, the United States, and Canada. ${ }^{10-13)}$ Although EoE can affect all age groups, most cases occur in children and in adults aged $30-50$ years. ${ }^{12,13)}$ A Japanese study aimed to determine the prevalence of EoE and PPI-responsive esophageal eosinophilic infiltration (R EEI) in Japanese patients in a multicenter study. Esophageal biopsy was performed when patients exhibited typical EoE symptoms or when endoscopic findings revealed a typical EoE appearance. Patients with EEI received PPI for 8 weeks to distinguish EoE from PPI-REE. A total of 13,634 subjects who underwent upper gastrointestinal endoscopy were enrolled. Seventy-one patients $(0.5 \%)$ with suspected EoE underwent biopsy examination. A histological examination of seven cases (9.9\%) revealed EEI. Two patients $(0.01 \%)$ were diagnosed with EoE and three patients $(0.02 \%)$ with PPI-R EEI. The authors concluded that EoE and PPI-R EEI were rare in Japanese patients who underwent upper gastrointestinal endoscopy. ${ }^{14)}$

Individuals with EoE usually experience other concomitant atopic/ allergic conditions including allergic rhinitis, bronchial asthma, food allergies, and eczema. ${ }^{15)}$

\section{GENETICS}

EoE has a strong familial association and $8 \%$ of parents of an EoE child have also been diagnosed with the disease. Additionally, siblings of EoE patients have 80 times the risk for developing the disease compared with the general population. In vitro studies have shown esophageal epithelial cells of EoE patients to have mutations in the filaggrin gene, which binds to keratin in epithelial cells and is central to barrier integrity in these cells. ${ }^{16)}$ Other studies have revealed genomic defects on chromosome 5q22, which is involved in T-helper cell 2 (Th2)-mediated cytokine pathways. ${ }^{17)}$ Later investigations using genome-wide association studies have demonstrated linkages with variants at the c11orf30 locus, STAT6 gene (allergic sensitization and serum immunoglobulin E [IgE]), and CAPN14 (calcium-regulated protease). ${ }^{18-20)}$ Ongoing research will better define the role of genetic inheritance and its contribution to the familial pattern observed in this evolving disease.

\section{PATHOGENESIS}

EoE may appear in genetically predisposed individuals after exposure 
of the esophagus to specific foods and aeroallergens, even though the exact mechanism remains unclear. ${ }^{21)}$ EoE is believed to be a multifactorial disease; environmental factors, food allergens, acid exposure, and genetic factors play a role in the pathogenesis of this disease. Normally, the esophagus is not infiltrated by eosinophils. However, in EoE, they accumulate in the esophageal mucosa through Th2- and IgE-mediated pathways, resembling the response observed in food allergies and GERD. This response model was validated in a previous study that demonstrated that only T cell-deficient-not B cell-deficient-mice were unable to develop EoE. ${ }^{22)}$

In the past, it was believed that adult-onset disease was caused by aero-allergens, while childhood disease was mainly secondary to food allergies. ${ }^{23)}$ Currently, it is firmly established that food allergies play a major role in the development of EoE both in adults and children. ${ }^{24,25)}$ Milk, wheat, soy, egg, peanuts, rye, beef, and beans are considered to be the most common food allergens. In the meantime, it has been shown that both groups are sensitized to aero-allergens, indicating their possible involvement in disease pathogenesis. ${ }^{26)}$ Esophageal epithelial cells exposed to acid(s) may result in enhanced permeability to potential allergens, which in turn may further contribute to the inflammatory cascade. ${ }^{27)}$

The release of eosinophil and mast cell products at the end of Th2mediated pathways leads to stimulation and regulation of inflammation and remodeling in the esophagus, mainly through profibrotic and proangiogenic factors. Subsequently, this process explains the main histological features of EoE-like subepithelial fibrosis and esophageal thickening, which in turn lead to characteristic endoscopic findings and the typical clinical manifestations of dysphagia and food impaction. ${ }^{28)}$

\section{CLINICAL PRESENTATION}

Typical presenting symptoms depend on age at presentation. The major symptoms in adults include esophageal dysphagia with solids (reported in $70 \%$ of cases) and food impaction, which necessitates endoscopic removal and usually leads to the diagnosis. ${ }^{29,30)}$ Other less typical symptoms in adults with EoE include abdominal pain, vomiting, chest pain, heartburn, and regurgitation. In children and infants, the most prevalent symptoms include reflux-like symptoms, vomiting, abdominal pain, food refusal, and failure to thrive. ${ }^{31)}$

A study by Lynch et al. ${ }^{32)}$ revealed that men generally present with typical symptoms, while women present with symptoms that mimic GERD. Because aeroallergens play a significant role in pathogenesis, EoE is diagnosed more commonly during the spring and summer, consistent with high counts of environmental pollens (grass, trees, and weeds). ${ }^{33)}$

\section{ROLE OF THE PRIMARY CARE PHYSICIAN IN THE DIAGNOSIS OF EOSINOPHILIC ESOPHAGITI}

The PCP is generally the first-contact health care provider for patients with suspected EoE; hence, awareness and vigilance of the PCP are crucial in identifying clinical features and symptoms suggestive of the disease and referring patients to appropriate work-up. The major "suggestive signs" of EoE are listed in Table 2. Differential diagnosis of EoE includes GERD, achalasia, eosinophilic gastroenteritis, esophageal candidiasis, drug-induced esophagitis, and connective tissue disorders. $^{1)}$

\section{COMPLEX INTERPLAY BETWEEN EOSINOPHILIC ESOPHAGITI, PROTON PUMP INHIBITOR- RESPONSIVE ESOPHAGEAL EOSINOPHILIA, AND GASTROESOPHAGEAL REFLUX DISEASE}

GERD and EoE constitute the most common esophageal disorders. Both share common features including esophageal symptoms, eosinophilic infiltration, and an increased prevalence in young adults. In routine clinical practice, GERD presents the most important differential diagnosis of EoE. Of note, both diseases largely coexist, with GERD established in up to one-half of EoE patients. ${ }^{2}$ The co-occurrence of EoE and GERD may take place within three clinical scenarios: both diseases incidentally co-exist but are unrelated to one another; GERD is the main disease and causes EoE (this hypothesis is explained by the fact that acid damage to the esophageal mucosa increases epithelial permeability, thus exposing deeper mucosal layers to antigens); or EoE is the main disease and causes GERD (this hypothesis is supported by the fact that EoE causes structural and motility changes in the lower esophageal sphincter and the esophageal body, which favor reflux) ${ }^{34)}$ Nevertheless, in clinical practice, the distinction between EoE and GERD was firmly established in consensus guidelines published in 2007. ${ }^{35)}$ Patients with esophageal symptoms and EoE, who either respond to PPI therapy or exhibit pathological acid exposure on $\mathrm{pH}$ monitoring, should be diagnosed with GERD. In contrast, patients with esophageal symptoms and EoE, who do not respond to PPI therapy nor exhibit pathological acid exposure on $\mathrm{pH}$ monitoring, should be diagnosed with EoE. The principle underlying this distinction is that GERD is the only disease that can cause esophageal symptoms, eosinophilia, and respond to PPI therapy. Nevertheless, the first case report of PPI-REE was published in 2006, in which the authors described three patients with confirmed EoE diagnosis based on clinical, endoscopic, and histological findings. The patients achieved complete

Table 2. Major "suggestive marks" of eosinophilic esophagitis

\begin{tabular}{l} 
Major suggestive marks \\
\hline Young male \\
Caucasian \\
Symptoms of dysphagia and food impaction \\
Symptoms exacerbation during spring and summer seasons \\
Gastroesophageal reflux disease-mimicking symptoms unresponsive to long-term \\
proton pump inhibitor \\
Personal or family history of allergic rhinitis, asthma, and/or food allergies \\
Family history of eosinophilic esophagitis
\end{tabular}


histological response with PPI therapy only. ${ }^{36)}$ This report has led to new perspectives and insight on disease understanding. Due to the rapidly evolving knowledge base regarding EoE, PPI-REE has been described as a new distinct phenotype of EoE. PPI-REE may also occur with normal esophageal acid exposure, thus emphasizing not only the complex interplay between GERD and EoE but also the probable nonanti-acidic effect of PPI therapy (mainly the anti-inflammatory effect via inhibition of the Th2-mediated allergic pathway). ${ }^{34)}$ As such, PPIREE should be excluded by means of a trial of PPI before confirming the diagnosis of EoE. ${ }^{30)}$ A Korean study published in 2013 aimed to aimed to analyze changes in symptoms, eosinophil count, and endoscopic findings in nine patients with EoE after treatment with PPI. The average endoscopic follow-up period was 10 months, ranging from 1 to 25 months. Symptoms and endoscopic and pathological findings at initial observation and follow-up were evaluated. Seven of the nine patients experienced symptom improvement and a reduced eosinophil count with PPI; however, the endoscopic findings generally did not improve. Two patients were unresponsive to PPI and were treated with corticosteroid, which resulted in symptomatic relief. ${ }^{37}$

Thus, the interaction between GERD and EoE is complex and knowledge in this area remains evolving. PPI-REE has emerged as an intermediate clinical phenotype, in between both GERD and EoE, with mounting evidence indicating that PPI-REE is a distinct phenotype of EoE. Further genetic and molecular research is essential to elucidate the different pathogenic pathways of EOE and PPI-REE entities, as well as clarify the reasons for the dissimilar responses to PPI therapy in the two conditions.

\section{DIAGNOSIS}

The initial diagnostic step in patients presenting with dysphagia, reflux-like symptoms non-responsive to PPI therapy, or any other symptoms suggestive of EoE is esophagogastroduodenoscopy, with multiple esophageal biopsies. ${ }^{1,38)}$ The five major endoscopic features of EoE-according to the EoE endoscopic reference score-include esophageal mucosal edema, ring formation, white exudates, furrows, and fibrotic strictures. ${ }^{39,40)}$ Additional endoscopic features include mucosal fragility, so called "crepe paper," and a narrow-caliber esophagus ${ }^{38,39)}$ A meta-analysis of 4,678 EoE patients by Kim et al. ${ }^{41)}$ aimed to define the prevalence and the diagnostic utility of these endoscopic findings in the diagnosis of EoE. Typical endoscopic findings were observed in $83 \%$ of patients with EoE. The pooled sensitivity of these findings was low (15\%-48\%), while the specificity was $>90 \%{ }^{41)}$ Therefore, typical endoscopic findings play an important role in the diagnosis of EoE, but they may not be present in all patients and the diagnosis of EoE cannot be established based on their presence. Endoscopist awareness is important while scoping a patient with suspected disease. $^{42)}$

Esophageal histology revealing pathological eosinophilic infiltration is the gold standard for diagnosing EoE. According to the most recent guidelines published in 2017, it is recommended that at least six biop- sies be obtained from the distal and proximal parts of the esophagus as well as from areas of endoscopic abnormality, mainly white exudates and longitudinal furrows. ${ }^{42)}$ It is also recommended to obtain samples from the duodenal and gastric mucosal biopsies to exclude eosinophilic gastroenteritis. ${ }^{42)}$ The accepted threshold for eosinophil density for the diagnosis of EoE is 15 eosinophils/high-power field (standard size, $0.3 \mathrm{~mm}^{2}$ ) in the esophageal mucosa, taken as the peak concentration in the specimens examined. ${ }^{43,44)}$ Additional histological findings include eosinophil abscesses, stromal fibrosis, dilated intercellular spaces, basal zone hyperplasia, and papillary elongation of squamous cells. ${ }^{45)}$

To confirm the diagnosis of EoE, eosinophilic infiltration should be isolated to the esophagus, persist after 8 weeks of twice-daily PPI treatment, and the exclusion of other causes of eosinophilia (Figure 1). ${ }^{43,46}$

\section{NON-INVASIVE BIOMARKERS: ANY ROLE IN DIAGNOSING EOSINOPHILIC ESOPHAGITIS?}

Although its diagnostic accuracy is very low, serum eosinophil level has consistently been shown to correlate with the degree of esophageal eosinophilia and decrease after histological remission of the disease. ${ }^{47-51)}$ Nevertheless, serum eosinophil count currently has no role in diagnosing or monitoring EoE. Several biomarkers, including serum IgE, eosinophil cationic protein, eosinophil-derived neurotoxin, and various chemokines, have failed to demonstrate any utility in diagnosing or monitoring the disease. ${ }^{52,53)}$

\section{MANAGEMENT}

The primary aim of treatment is to improve patient symptoms and quality of life, as well as to prevent esophageal structural and functional complications. Active EoE interferes with food intake and is associated with symptoms of dysphagia, food impaction, and impaired quality of life. ${ }^{54)}$ Chronic inflammation leads to esophageal tissue remodeling and stricture(s) formation, which results in decreased esophageal compliance and increased stiffness, subsequently inducing symptoms of dysphagia and food impaction. ${ }^{55)}$ Long-term treatment studies with topical steroids have shown that remodeling can be prevented or reversed with therapy. ${ }^{56)}$ Currently, topical corticosteroids, dietary modification, and esophageal balloon dilation are the primary modalities of EoE treatment. Either diet modification or topical steroids may be proposed as first-line therapy. This should be individually discussed with the patient and may potentially be switchable over time. The effcacy of any therapy should be assessed by endoscopy and histology after a 6to 12 -week interval from treatment initiation. ${ }^{42,46)}$ Maintenance treatment after the induction phase is reasonable due to the chronic, relapsing inflammatory nature of the disease; however, there are still no available guidelines addressing maintenance protocols by means of drugs doses, duration, and monitoring (Figure 2).

According to the American College of Gastroenterology guidelines published in 2013, therapy endpoints include improvement in clinical 


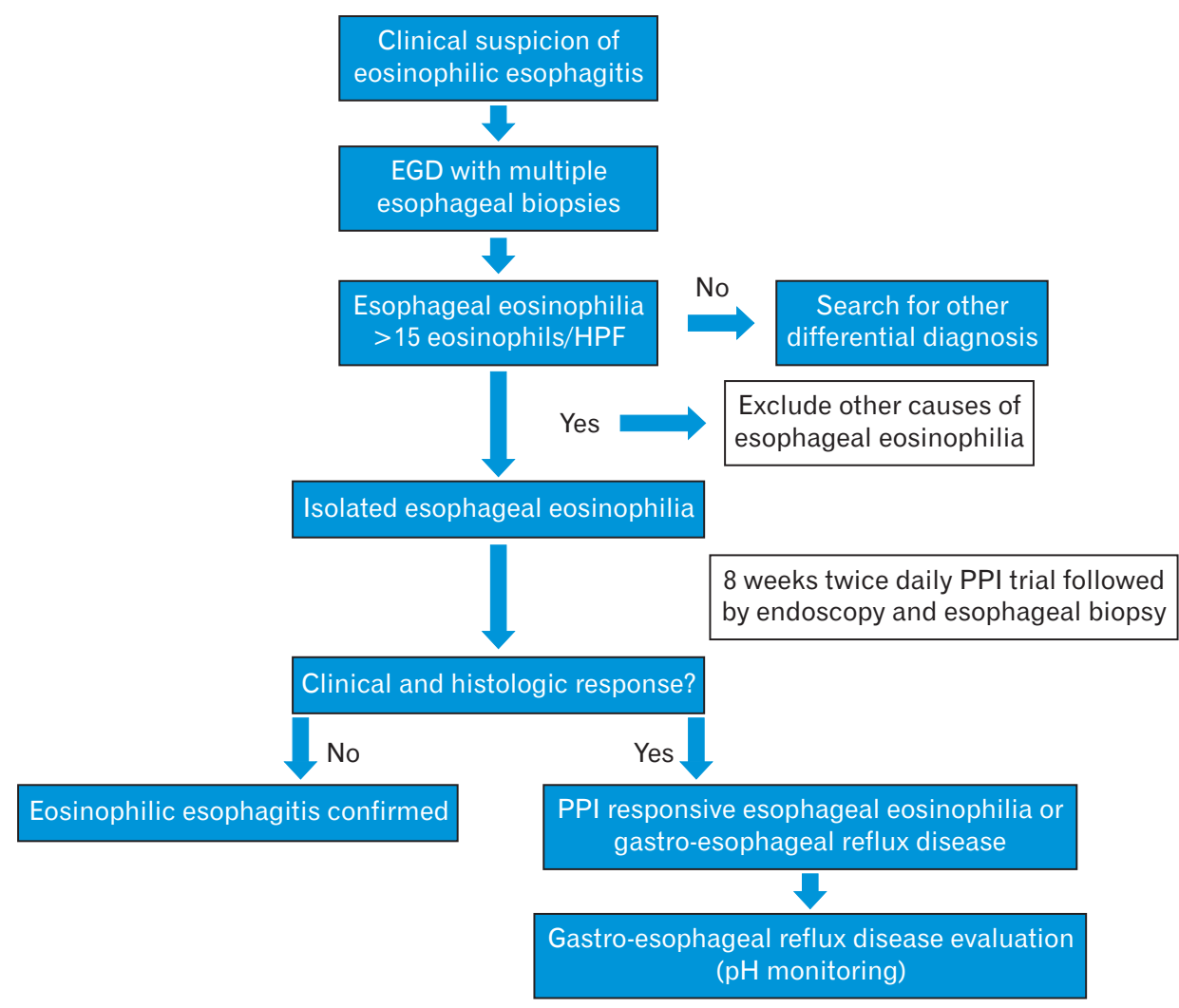

Figure 1. Diagnostic approach to eosinophilic esophagitis. EGD, esophagogastroduodenoscopy; HPF, high-power field; PPI, proton pump inhibitor. symptoms and esophageal eosinophilic inflammation. While complete resolution of symptoms and pathology is an ideal therapy endpoint, it remains an unrealistic goal in clinical practice. ${ }^{46)}$ A multidisciplinary approach with the collaboration of a gastroenterologist, PCP, allergist, pathologist, and dietitian should be implemented as the favored strategy for patient care.

\section{PHARMACOLOGICAL THERAPY}

Oral topical corticosteroids have become the first-line medical therapy in adult patients. ${ }^{57)}$ The efficacy of topical steroids for histological remission has been confirmed in several randomized trials. Fluticasone propionate inhaler $(880 \mu \mathrm{g})$ puffed directly into the mouth and then dry swallowed twice per day for 6-8 weeks has been proven to be effective in reducing symptoms and EoE. ${ }^{58-64)}$ Patients are advised to avoid food or drink for 30 minutes to prevent rinsing the medication from the esophageal mucosa. Oral viscous budesonide (OVB) has been shown to have a longer contact time with the esophageal mucosa due to its high viscosity. OVB ( $1 \mathrm{mg}$ ) twice per day for 8 weeks has been shown to decrease esophageal symptoms and reduce EoE. ${ }^{48)}$ Because only $1 \%$ of the topical steroid is absorbed, systemic side effects are extremely rare, although oral and esophageal candidiasis can occur in $5 \%-26 \%$ of patients. ${ }^{48,64)}$ Systemic corticosteroids are effective drugs for inducing clinical and histological remission in patients with EoE; however, they are not recommended as a first-line pharmacological therapy due to the high rate of systemic side effects. ${ }^{42,46)}$
In case of topical steroid failure, prolonged or higher doses of topical steroids, systemic steroids, dietary modification, or esophageal dilation should be attempted to achieve symptomatic improvement (Figure 1$)^{42,46)}$

\section{EMERGING DRUGS}

The efficacy and safety of several new drugs are currently being investigated for the treatment of EoE. In a previous case series, immunomodulators (azathioprine and 6mercaptopurine) induced and maintained clinical and histological remission in patients with steroid-dependent EoE. ${ }^{65)}$ A mast cell stabilizer, cromolyn sodium, demonstrated negative results in EoE patients. ${ }^{66)}$ Montelukast, which is an eosinophil-stabilizing agent, has been shown to improve clinical symptoms but without histological improvement. ${ }^{67)}$ Biological treatment, antiinterleukin 5, and interleukin-13 antibodies have been shown to reduce eosinophilia but with very mild symptomatic improvement. ${ }^{68-70)}$ Nevertheless, randomized controlled trials aimed at better defining the efficacy and safety of these novel emerging drugs and to determine their role in treatment strategies for EoE, are warranted.

\section{DIETARY MODIFICATION}

Dietary modification is considered to be an effective treatment option for EoE. Most research investigating dietary treatments for EoE have been conducted in pediatric populations; therefore, there are less data 


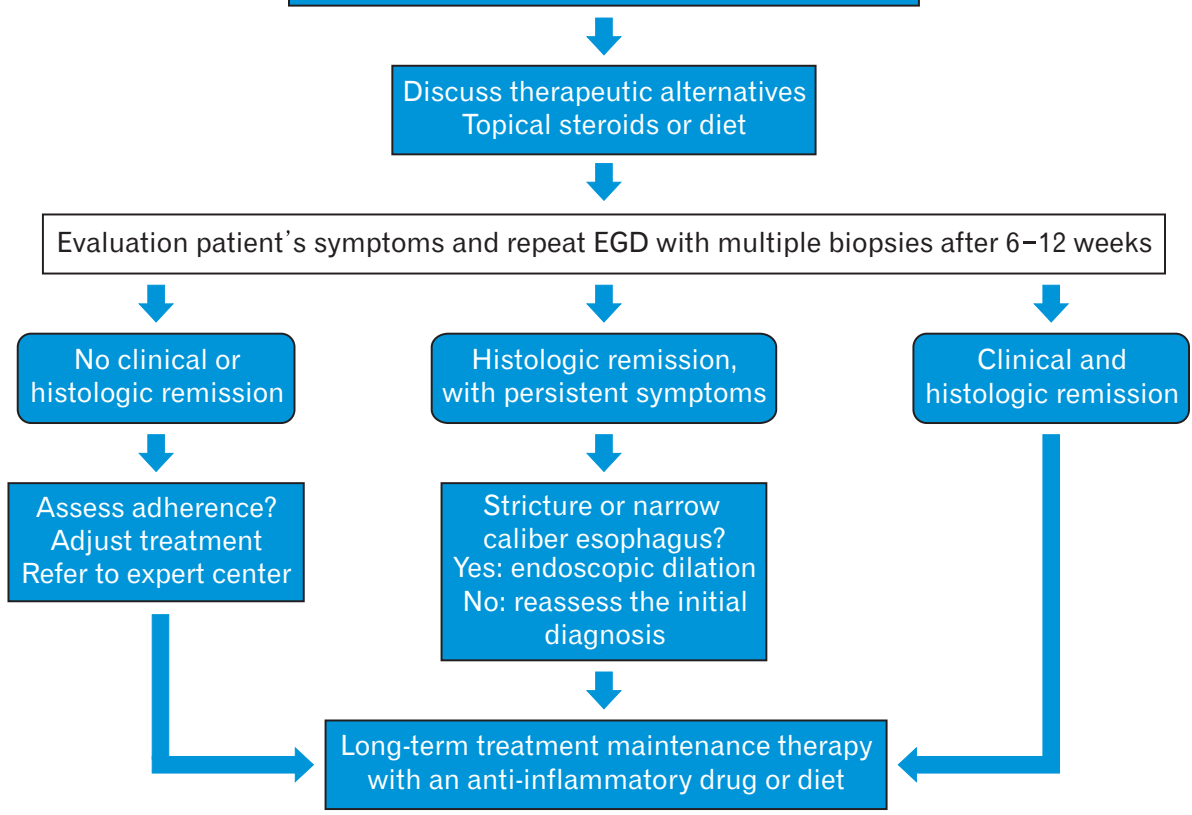

Figure 2. Management of eosinophilic esophagitis. EGD, esophagogastroduodenoscopy. and evidence regarding the adult population. Diet modification could be recommended as an initial therapeutic modality or when other treatment modalities have failed. There are three major strategies of dietary therapy: total elimination of all food allergens, replaced with elemental or amino acid-based formulas; targeted elimination diet(s) based on allergy testing; and an empirical six-food elimination diet removing soy, egg, milk, wheat, nuts, and seafood. Generally, the treatment period is $4-8$ weeks, followed by a stepwise reintroduction of foods once clinical and histological remission has been achieved. Kelly et al. ${ }^{71)}$ reported that an elemental diet administered for a period of 6 weeks achieved both symptomatic and histological remission in $95 \%$ of EoE patients. However, the elemental diet is very restrictive, expensive, and affects patient quality of life. ${ }^{71)}$ The six-food elimination diet is effective in achieving histological and clinical remission in approximately three-quarters of adult EoE patients. ${ }^{72)}$ A study by Molina-Infante et al. ${ }^{73)}$ revealed that 6 weeks of four food group elimination diet (exclusion of milk, egg, wheat, and legumes) achieved clinical and pathological remission in $54 \%$ of adult EoE patients. The efficacy of allergy tests in clinical practice for the identification of food triggers of EoE has been confirmed to be low in adults, and their use in clinical practice is controversial. ${ }^{42,46)}$ This therapy is directed by recognition of food allergens by skin prick or patch tests, as well as blood tests. Wolf et al. ${ }^{74)}$ reported that $68 \%$ of EoE patients experienced symptomatic improvement with targeted therapy; however, histological remission was achieved in only one-third of patients. This option should be discussed properly with the patient and be offered as per the patient's preference because it is the least effective.

A dietitian specialized in food allergies and EoE should be involved in the management of patients with EoE. Collaboration with an allergist is important to determine which allergens trigger EoE, and to search for other comorbidities such as asthma, atopic dermatitis, and other allergic conditions.

Dietary treatment, however, has several drawbacks. It is expensive, time and resource consuming, and restrictive. Thus, the decision to follow this approach should be individualized based on available resources and patient preferences.

\section{ENDOSCOPIC THERAPY}

In the emergency scenario of food impaction, endoscopic intervention is critical for the relief of symptoms and the prevention of complications. Moreover, esophageal dilation has a fundamental role in the management of EoE. The major indications for esophageal dilation include the following: disease refractory to pharmacological or dietary therapy; the presence of esophageal stricture; and narrow caliber esophagus. Esophageal dilation has been proven to reduce patient symptoms and improve quality of life. ${ }^{75)}$ Esophageal diameter should be dilated to $15-18 \mathrm{~mm}$ to relieve dysphagia, and multiple sessions may be necessary to achieve this goal. It is generally a safe procedure, with two main possible complications, post-dilation chest pain for few days and a very low risk for esophageal perforation $(0.1 \%){ }^{76,77)}$

\section{CONCLUSION}

In conclusion, EoE is an emerging disease that causes dysphagia, food impaction, negatively affects quality of life and, furthermore, represents a significant cause of gastrointestinal morbidity. Understanding of the disease has advanced dramatically over the past two decades due to extensive clinical, molecular, and genetic research. Clinician familiarity with symptoms suggestive of the disease is of paramount im- 
portance to promptly refer patients to appropriate care. Endoscopy with histology revealing pathological eosinophilic dominant inflammation isolated to the esophagus is the most significant initial step in the diagnosis. A trial of PPI is mandatory to rule out GERD or PPI-REE entities. Topical corticosteroids, diet modification, and esophageal balloon dilation are the primary modalities of EoE treatment. Either diet or topical steroids may be proposed as first-line therapy. The knowledge base regarding newly emerging drugs, such as anti-allergic, immunomodulators, and biologicals is still evolving, and further randomized controlled trials are warranted to better define their role in the treatment algorithm of EoE patients. The role of the PCP as the first medical care provider is of paramount importance in suspecting the disease and referring patients for appropriate diagnosis, as well as in collaborating with the gastroenterologist, dietician, allergist, and pathologist for delivering the highest level of patient care.

\section{CONFLICT OF INTEREST}

No potential conflict of interest relevant to this article was reported.

\section{ACKNOWLEDGMENTS}

The authors acknowledge Mrs. Ruba Dacca and Mrs. Lana Ginini for their assistance with preparing the figures and structuring the final version of the manuscript.

\section{ORCID}

Amir Mari: https://orcid.org/0000-0002-6828-4738

Emmanouela Tsoukali: https://orcid.org/0000-0003-3366-6952

Afif Yaccob: https://orcid.org/0000-0003-3058-5583

\section{REFERENCES}

1. Liacouras CA, Furuta GT, Hirano I, Atkins D, Attwood SE, Bonis PA, et al. Eosinophilic esophagitis: updated consensus recommendations for children and adults. J Allergy Clin Immunol 2011;128:3-20.

2. Molina-Infante J, Ferrando-Lamana L, Ripoll C, Hernandez-Alonso M, Mateos JM, Fernandez-Bermejo M, et al. Esophageal eosinophilic infiltration responds to proton pump inhibition in most adults. Clin Gastroenterol Hepatol 2011;9:110-7.

3. Weller PF. The immunobiology of eosinophils. N Engl J Med 1991;324: 1110-8.

4. Winter HS, Madara JL, Stafford RJ, Grand RJ, Quinlan JE, Goldman H. Intraepithelial eosinophils: a new diagnostic criterion for reflux esophagitis. Gastroenterology 1982;83:818-23.

5. Landres RT, Kuster GG, Strum WB. Eosinophilic esophagitis in a patient with vigorous achalasia. Gastroenterology 1978;74:1298-301.

6. Picus D, Frank PH. Eosinophilic esophagitis. AJR Am J Roentgenol 1981;136:1001-3.

7. Munch R, Kuhlmann U, Makek M, Ammann R, Siegenthaler W. Eosinophilic esophagitis, a rare manifestation of eosinophilic gastroenteri- tis. Schweiz Med Wochenschr 1982;112:731-4.

8. Attwood SE, Smyrk TC, Demeester TR, Jones JB. Esophageal eosinophilia with dysphagia: a distinct clinicopathologic syndrome. Dig Dis Sci 1993;38:109-16.

9. Hruz P. Epidemiology of eosinophilic esophagitis. Dig Dis 2014;32:407.

10. Giriens B, Yan P, Safroneeva E, Zwahlen M, Reinhard A, Nydegger A, et al. Escalating incidence of eosinophilic esophagitis in Canton of Vaud, Switzerland, 1993-2013: a population-based study. Allergy 2015;70:1633-9.

11. Prasad GA, Alexander JA, Schleck CD, Zinsmeister AR, Smyrk TC, Elias RM, et al. Epidemiology of eosinophilic esophagitis over three decades in Olmsted County, Minnesota. Clin Gastroenterol Hepatol 2009; 7:1055-61.

12. Dellon ES, Jensen ET, Martin CF, Shaheen NJ, Kappelman MD. Prevalence of eosinophilic esophagitis in the United States. Clin Gastroenterol Hepatol 2014;12:589-96.

13. Noel RJ, Putnam PE, Rothenberg ME. Eosinophilic esophagitis. N Engl J Med 2004;351:940-1.

14. Fujiwara Y, Sugawa T, Tanaka F, Tatsuwaki H, Okuyama M, Hayakawa $\mathrm{T}$, et al. A multicenter study on the prevalence of eosinophilic esophagitis and PPI-responsive esophageal eosinophilic infiltration. Intern Med 2012;51:3235-9.

15. Assiri AM, Saeed A. Incidence and diagnostic features of eosinophilic esophagitis in a group of children with dysphagia and gastroesophageal reflux disease. Saudi Med J 2014;35:292-7.

16. Blanchard C, Stucke EM, Burwinkel K, Caldwell JM, Collins MH, Ahrens A, et al. Coordinate interaction between IL-13 and epithelial differentiation cluster genes in eosinophilic esophagitis. J Immunol 2010;184:4033-41.

17. Rothenberg ME, Spergel JM, Sherrill JD, Annaiah K, Martin LJ, Cianferoni A, et al. Common variants at 5q22 associate with pediatric eosinophilic esophagitis. Nat Genet 2010;42:289-91.

18. Amaral AF, Minelli C, Guerra S, Wjst M, Probst-Hensch N, Pin I, et al. The locus C11orf30 increases susceptibility to poly-sensitization. Allergy 2015;70:328-33.

19. Bonnelykke K, Matheson MC, Pers TH, Granell R, Strachan DP, Alves AC, et al. Meta-analysis of genome-wide association studies identifies ten loci influencing allergic sensitization. Nat Genet 2013;45:902-6.

20. Hsu CY, Henry J, Raymond AA, Mechin MC, Pendaries V, Nassar D, et al. Deimination of human filaggrin-2 promotes its proteolysis by calpain 1. J Biol Chem 2011;286:23222-33.

21. Raheem M, Leach ST, Day AS, Lemberg DA. The pathophysiology of eosinophilic esophagitis. Front Pediatr 2014;2:41.

22. Simon HU, Straumann A. Immunopathogenesis of eosinophilic esophagitis. Dig Dis 2014;32:11-4.

23. Straumann A, Aceves SS, Blanchard C, Collins MH, Furuta GT, Hirano I, et al. Pediatric and adult eosinophilic esophagitis: similarities and differences. Allergy 2012;67:477-90.

24. Gonsalves N, Yang GY, Doerfler B, Ritz S, Ditto AM, Hirano I. Elimination diet effectively treats eosinophilic esophagitis in adults; food reintroduction identifies causative factors. Gastroenterology 2012;142: 1451-9.

25. Lucendo AJ, Arias A, Gonzalez-Cervera J, Yague-Compadre JL, Guagnozzi D, Angueira T, et al. Empiric 6-food elimination diet induced 
and maintained prolonged remission in patients with adult eosinophilic esophagitis: a prospective study on the food cause of the disease. J Allergy Clin Immunol 2013;131:797-804.

26. Simon D, Straumann A, Simon HU. Eosinophilic esophagitis and allergy. Dig Dis 2014;32:30-3.

27. Tobey NA, Hosseini SS, Argote CM, Dobrucali AM, Awayda MS, Orlando RC. Dilated intercellular spaces and shunt permeability in nonerosive acid-damaged esophageal epithelium. Am J Gastroenterol 2004;99:13-22.

28. Croese J, Fairley SK, Masson JW, Chong AK, Whitaker DA, Kanowski PA, et al. Clinical and endoscopic features of eosinophilic esophagitis in adults. Gastrointest Endosc 2003;58:516-22.

29. Muller S, Puhl S, Vieth M, Stolte M. Analysis of symptoms and endoscopic findings in 117 patients with histological diagnoses of eosinophilic esophagitis. Endoscopy 2007;39:339-44.

30. Dellon ES, Gibbs WB, Fritchie KJ, Rubinas TC, Wilson LA, Woosley JT, et al. Clinical, endoscopic, and histologic findings distinguish eosinophilic esophagitis from gastroesophageal reflux disease. Clin Gastroenterol Hepatol 2009;7:1305-13.

31. Spergel JM, Brown-Whitehorn TF, Beausoleil JL, Franciosi J, Shuker M, Verma R, et al. 14 Years of eosinophilic esophagitis: clinical features and prognosis. J Pediatr Gastroenterol Nutr 2009;48:30-6.

32. Lynch KL, Dhalla S, Chedid V, Ravich WJ, Stein EM, Montgomery EA, et al. Gender is a determinative factor in the initial clinical presentation of eosinophilic esophagitis. Dis Esophagus 2016;29:174-8.

33. Moawad FJ, Veerappan GR, Lake JM, Maydonovitch CL, Haymore BR, Kosisky SE, et al. Correlation between eosinophilic oesophagitis and aeroallergens. Aliment Pharmacol Ther 2010;31:509-15.

34. Spechler SJ, Genta RM, Souza RF. Thoughts on the complex relationship between gastroesophageal reflux disease and eosinophilic esophagitis. Am J Gastroenterol 2007;102:1301-6.

35. Furuta GT, Liacouras CA, Collins MH, Gupta SK, Justinich C, Putnam PE, et al. Eosinophilic esophagitis in children and adults: a systematic review and consensus recommendations for diagnosis and treatment. Gastroenterology 2007;133:1342-63.

36. Ngo P, Furuta GT, Antonioli DA, Fox VL. Eosinophils in the esophagus: peptic or allergic eosinophilic esophagitis?: case series of three patients with esophageal eosinophilia. Am J Gastroenterol 2006;101: 1666-70.

37. Lee JH, Kim MJ, Kim JH, Youn YH, Kim N, Bak YT, et al. Clinical analysis of primary eosinophilic esophagitis. J Neurogastroenterol Motil 2013;19:204-9.

38. Von Arnim U, Miehlke S, Madisch A, Vieth M, Straumann A, Malfertheiner P. Eosinophilic esophagitis: update - pathogenesis, diagnosis and therapy. Z Gastroenterol 2014;52:296-305.

39. Straumann A, Spichtin HP, Bucher KA, Heer P, Simon HU. Eosinophilic esophagitis: red on microscopy, white on endoscopy. Digestion 2004;70:109-16.

40. Peery AF, Cao H, Dominik R, Shaheen NJ, Dellon ES. Variable reliability of endoscopic findings with white-light and narrow-band imaging for patients with suspected eosinophilic esophagitis. Clin Gastroenterol Hepatol 2011;9:475-80.

41. Kim HP, Vance RB, Shaheen NJ, Dellon ES. The prevalence and diagnostic utility of endoscopic features of eosinophilic esophagitis: a meta-analysis. Clin Gastroenterol Hepatol 2012;10:988-96.
42. Lucendo AJ, Molina-Infante J, Arias A, von Arnim U, Bredenoord AJ, Bussmann C, et al. Guidelines on eosinophilic esophagitis: evidencebased statements and recommendations for diagnosis and management in children and adults. United European Gastroenterol J 2017;5:335-58.

43. Peery AF, Shaheen NJ, Dellon ES. Practice patterns for the evaluation and treatment of eosinophilic oesophagitis. Aliment Pharmacol Ther 2010;32:1373-82.

44. Sperry SL, Shaheen NJ, Dellon ES. Toward uniformity in the diagnosis of eosinophilic esophagitis (EoE): the effect of guidelines on variability of diagnostic criteria for EoE. Am J Gastroenterol 2011;106:824-32.

45. Collins MH. Histopathologic features of eosinophilic esophagitis and eosinophilic gastrointestinal diseases. Gastroenterol Clin North Am 2014;43:257-68.

46. Dellon ES, Gonsalves N, Hirano I, Furuta GT, Liacouras CA, Katzka DA, et al. ACG clinical guideline: evidenced based approach to the diagnosis and management of esophageal eosinophilia and eosinophilic esophagitis (EoE). Am J Gastroenterol 2013;108:679-92.

47. Konikoff MR, Blanchard C, Kirby C, Buckmeier BK, Cohen MB, Heubi JE, et al. Potential of blood eosinophils, eosinophil-derived neurotoxin, and eotaxin-3 as biomarkers of eosinophilic esophagitis. Clin Gastroenterol Hepatol 2006;4:1328-36.

48. Straumann A, Conus S, Degen L, Felder S, Kummer M, Engel H, et al. Budesonide is effective in adolescent and adult patients with active eosinophilic esophagitis. Gastroenterology 2010;139:1526-37.

49. Filik L. Montelukast and maintenance of steroid-induced remission in eosinophilic esophagitis. Dig Dis Sci 2012;57:258-9.

50. Rodriguez-Sanchez J, Gomez-Torrijos E, de-la-Santa-Belda E, LopezViedma B, Martin-Davila F, Pilkington-Woll JP, et al. Effectiveness of serological markers of eosinophil activity in monitoring eosinophilic esophagitis. Rev Esp Enferm Dig 2013;105:462-7.

51. Schlag C, Miehlke S, Heiseke A, Brockow K, Krug A, von Arnim U, et al. Peripheral blood eosinophils and other non-invasive biomarkers can monitor treatment response in eosinophilic oesophagitis. Aliment Pharmacol Ther 2015;42:1122-30.

52. Min SB, Nylund CM, Baker TP, Ally M, Reinhardt B, Chen YJ, et al. Longitudinal evaluation of noninvasive biomarkers for eosinophilic esophagitis. J Clin Gastroenterol 2017;51:127-35.

53. Rao GS, Mitchell L, Ohnuki L, Fitzgerald J, Gleich GJ, Corkins M, et al. Can eosinophil derived neurotoxin (EDN) act as a surrogate marker of disease activity in children with allergic eosinophilic esophagitis (AEE)? Gastrointest Endosc 2004;59:P103.

54. Franciosi JP, Hommel KA, Bendo CB, King EC, Collins MH, Eby MD, et al. PedsQL eosinophilic esophagitis module: feasibility, reliability, and validity. J Pediatr Gastroenterol Nutr 2013;57:57-66.

55. Mishra A, Wang M, Pemmaraju VR, Collins MH, Fulkerson PC, Abonia JP, et al. Esophageal remodeling develops as a consequence of tissue specific IL-5-induced eosinophilia. Gastroenterology 2008;134:204-14.

56. Aceves SS, Newbury RO, Chen D, Mueller J, Dohil R, Hoffman H, et al. Resolution of remodeling in eosinophilic esophagitis correlates with epithelial response to topical corticosteroids. Allergy 2010;65:109-16.

57. Carr S, Watson W. Eosinophilic esophagitis. Allergy Asthma Clin Immunol 2011;7 Suppl 1:S8.

58. Moawad FJ, Veerappan GR, Dias JA, Baker TP, Maydonovitch CL, Wong RK. Randomized controlled trial comparing aerosolized swal- 
lowed fluticasone to esomeprazole for esophageal eosinophilia. Am J Gastroenterol 2013;108:366-72.

59. Peterson KA, Thomas KL, Hilden K, Emerson LL, Wills JC, Fang JC. Comparison of esomeprazole to aerosolized, swallowed fluticasone for eosinophilic esophagitis. Dig Dis Sci 2010;55:1313-9.

60. Dellon ES, Sheikh A, Speck O, Woodward K, Whitlow AB, Hores JM, et al. Viscous topical is more effective than nebulized steroid therapy for patients with eosinophilic esophagitis. Gastroenterology 2012;143: 321-4.

61. Butz BK, Wen T, Gleich GJ, Furuta GT, Spergel J, King E, et al. Efficacy, dose reduction, and resistance to high-dose fluticasone in patients with eosinophilic esophagitis. Gastroenterology 2014;147:324-33.

62. Miehlke S, Hruz P, Vieth M, Bussmann C, von Arnim U, Bajbouj M, et al. A randomised, double-blind trial comparing budesonide formulations and dosages for short-term treatment of eosinophilic oesophagitis. Gut 2016;65:390-9.

63. Tan ND, Xiao YL, Chen MH. Steroids therapy for eosinophilic esophagitis: systematic review and meta-analysis. J Dig Dis 2015;16:431-42.

64. Remedios M, Campbell C, Jones DM, Kerlin P. Eosinophilic esophagitis in adults: clinical, endoscopic, histologic findings, and response to treatment with fluticasone propionate. Gastrointest Endosc 2006;63:312.

65. Netzer P, Gschossmann JM, Straumann A, Sendensky A, Weimann R, Schoepfer AM. Corticosteroid-dependent eosinophilic oesophagitis: azathioprine and 6-mercaptopurine can induce and maintain longterm remission. Eur J Gastroenterol Hepatol 2007;19:865-9.

66. Liacouras CA, Spergel JM, Ruchelli E, Verma R, Mascarenhas M, Semeao E, et al. Eosinophilic esophagitis: a 10-year experience in 381 children. Clin Gastroenterol Hepatol 2005;3:1198-206.

67. Attwood SE, Lewis CJ, Bronder CS, Morris CD, Armstrong GR, Whittam J. Eosinophilic oesophagitis: a novel treatment using Montelukast. Gut 2003;52:181-5.

68. Straumann A, Conus S, Grzonka P, Kita H, Kephart G, Bussmann C, et al. Anti-interleukin-5 antibody treatment (mepolizumab) in active eo- sinophilic oesophagitis: a randomised, placebo-controlled, doubleblind trial. Gut 2010;59:21-30.

69. Spergel JM, Rothenberg ME, Collins MH, Furuta GT, Markowitz JE, Fuchs G 3rd, et al. Reslizumab in children and adolescents with eosinophilic esophagitis: results of a double-blind, randomized, placebocontrolled trial. J Allergy Clin Immunol 2012;129:456-63.

70. Rothenberg ME, Wen T, Greenberg A, Alpan O, Enav B, Hirano I, et al. Intravenous anti-IL-13 mAb QAX576 for the treatment of eosinophilic esophagitis. J Allergy Clin Immunol 2015;135:500-7.

71. Kelly KJ, Lazenby AJ, Rowe PC, Yardley JH, Perman JA, Sampson HA. Eosinophilic esophagitis attributed to gastroesophageal reflux: improvement with an amino acid-based formula. Gastroenterology 1995;109:1503-12.

72. Kagalwalla AF, Sentongo TA, Ritz S, Hess T, Nelson SP, Emerick KM, et al. Effect of six-food elimination diet on clinical and histologic outcomes in eosinophilic esophagitis. Clin Gastroenterol Hepatol 2006;4:1097-102.

73. Molina-Infante J, Arias A, Barrio J, Rodriguez-Sanchez J, Sanchez-Cazalilla M, Lucendo AJ. Four-food group elimination diet for adult eosinophilic esophagitis: a prospective multicenter study. J Allergy Clin Immunol 2014;134:1093-9.

74. Wolf WA, Jerath MR, Sperry SL, Shaheen NJ, Dellon ES. Dietary elimination therapy is an effective option for adults with eosinophilic esophagitis. Clin Gastroenterol Hepatol 2014;12:1272-9.

75. Schoepfer AM, Gonsalves N, Bussmann C, Conus S, Simon HU, Straumann A, et al. Esophageal dilation in eosinophilic esophagitis: effectiveness, safety, and impact on the underlying inflammation. Am J Gastroenterol 2010;105:1062-70.

76. Bohm ME, Richter JE. Review article: oesophageal dilation in adults with eosinophilic oesophagitis. Aliment Pharmacol Ther 2011;33:74857.

77. Jacobs JW Jr, Spechler SJ. A systematic review of the risk of perforation during esophageal dilation for patients with eosinophilic esophagitis. Dig Dis Sci 2010;55:1512-5. 